\title{
PROPOSTA DE AVALIAÇÃO ECONÔMICO-FINANCEIRA DO PROGRAMA DE REESTRUTURAÇÃO E EXPANSÃO DAS UNIVERSIDADES FEDERAIS BRASILEIRAS NA UFPEL
}

\author{
João Carlos de Oliveira Koglin \\ Universidade Federal de Pelotas (UFPEL) \\ Vera Maria Ribeiro Nogueira \\ Universidade Federal de Santa Catarina (UFSC)
}

PROPOSTA DE AVALIAÇÃO ECONÔMICO-FINANCEIRA DO PROGRAMA DE REESTRUTURAÇÃO E EXPANSÃO DAS UNIVERSIDADES FEDERAIS BRASILEIRAS NA UFPEL

Resumo: Este artigo tem como objetivo apresentar uma proposta de avaliação econômico-financeira do Programa de Reestruturação e Expansão das Universidades Federais (REUNI) na Universidade Federal de Pelotas. Considera a política nacional de expansão da educação superior pública definida como balizadora das ações a serem implementadas pela UFPEL no período de 2008 a 2012. Aborda, referenciado em pesquisa, a temática de avaliação de políticas públicas, destacando sua importância como instrumento para quem formula e implementa estas políticas. Indica que a avaliação tem a capacidade de potencializar a correção dos rumos da política empregada, e que esta proposição trará melhorias à implementação do programa, fortalecimento da cultura de avaliação e monitoramento na comunidade acadêmica e criação de parâmetros que possam ser utilizados por outras instituições similares.

Palavras-chave: Política pública, Programa REUNI, avaliação de políticas, educação superior.

PROPOSAL FOR AN ECONOMIC AND FINANCIAL EVALUATION OF THE RESTRUCTURING AND EXPANSION PROGRAM OF FEDERAL BRAZILIAN UNIVERSITIES IN UFPEL

Abstract: This article presents a proposal for an economic and financial evaluation of the Restructuring and Expansion Program of Federal Brazilian Universities (REUNI) as applied at the Federal University at Pelotas (UFPEL). It considered this national policy for expansion of public higher education, which set the guidelines for actions undertaken by UFPEL form 2008-2012. The article focuses on the theme of evaluation because considering the context and discourse of constant scarcity of resources for the implementation of public policies, evaluation is an important tool for those who prepare and execute these policies. An evaluation can help correct the direction of the policies adopted and to attain the objectives and goals. The proposal includes the creation of parameters that can be used by other similar institutions and the strengthening of a democratic culture of evaluation and monitoring in the academic community to improve the chances for effective results from the program in the medium and long term.

Key words: Public policy, REUNI program, policy evaluation, higher education. 


\section{INTRODUÇÃO}

Atualmente, um dos grandes entraves que temos que superar é a desigualdade entre os níveis de educação no Brasil, tanto em relação às taxas de alfabetização como na comparação da taxa de atendimento da educação básica com a superior.

Neste sentido, segundo o Instituto Nacional de Estudos e Pesquisas Educacionais (INEP) (2008) as taxas de analfabetismo da população brasileira acima de 14 anos, em 2008, eram as seguintes: na região norte de $11,0 \%$, na nordeste $19,4 \%$, na centro-oeste $8,0 \%$, na sudeste $5,5 \%$ e na região Sul $5,5 \%$. Desta forma a média nacional apresentou uma taxa de $10 \%$.

Os percentuais acima apresentados são alarmantes, principalmente na região nordeste, que tinha uma taxa de analfabetismo na população com idade superior a 14 anos de $19,4 \%$.

Ao mesmo tempo, segundo o mesmo instituto acima referido, em 2008 as taxas de atendimento da educação no Brasil eram as seguintes: em nível da educação fundamental $95 \%$, no ensino médio $48 \%$ e no ensino superior $13 \%$ de atendimento.

A partir dos dados acima, podemos entender por que as políticas públicas para a Educação Superior ganharam tanto destaque nos últimos anos com a implementação de programas que pudessem diminuir o déficit social em nosso país. Isto porque, pode-se facilmente afirmar que as políticas de universalização do acesso e da permanência à educação básica foram, em grande parte, uma conquista histórica enfrentada em décadas anteriores, possibilitando o acesso à quase totalidade da população em idade escolar.

No entanto, também, se pode dizer que o grande desafio das atuais políticas públicas para a educação se encontra focado no ensino superior como forma de garantia do acesso e do sucesso de um grande contingente de jovens e de adultos até então excluídos do mesmo.

Na perspectiva de promover a educação para todos, em todos os níveis de ensino, as atuais políticas educacionais buscam articular, especialmente, dois movimentos: a expansão do acesso ao ensino superior, por meio do aumento quantitativo na oferta de vagas das Instituições Federais de Ensino Superiores (IFES) já existentes e a interiorização da educação superior através da criação de novas universidades, de campus fora de sede e de polos de apoio presencial às universidades públicas.

Fazendo um recorte dos dados apresentados, segundo o próprio INEP/MEC, o Brasil, em 2008, tinha 23.242.000 jovens com idade entre 18 e 24 anos, e destes apenas 3.221 .000 (13,9\%) estavam matriculados no Ensino Superior. O grande desafio de nosso país é sem dúvida ofertar mais vagas para o ensino médio e, principalmente, para o superior (INSTITUTO NACIONAL DE ESTUDOS E
PESQUISAS EDUCACIONAIS ANÍSIO TEIXEIRA, 2011).

Neste contexto, o Governo Federal criou o Programa de Apoio a Planos de Reestruturação e Expansão das Universidades Federais (REUNI) do Ministério da Educação (MEC), que foi instituído pelo Decreto $n .{ }^{\circ} 6.096$, de 24 de abril de 2007. Este programa apresentava como um dos principais objetivos dotar as universidades federais das condições necessárias para ampliação do acesso e permanência de estudantes na educação superior, em nível de graduação, o aumento da qualidade dos cursos e o melhor aproveitamento da estrutura física e de recursos humanos (BRASIL, 2007).

O Programa REUNI é considerado uma das ações integrantes do Plano de Desenvolvimento da Educação (PDE), reconhecendo o papel estratégico das universidades para o desenvolvimento econômico e social de nosso país. O programa tem como propósito agrupar empenhos para consolidação de uma política nacional de expansão da educação superior pública.

Como vimos anteriormente, o Brasil precisa urgentemente expandir a oferta de vagas nas universidades, principalmente as públicas, para atender o novo PDE e o Plano Nacional de Educação, Lei $n^{\circ} 10.172 / 2001$, que estabelece como uma de suas metas principais expandir a oferta de educação superior para atender $30 \%$ dos jovens na faixa etária de 18 e 24 anos (BRASIL, 2001).

Diante dos objetivos propostos pelo Programa REUNI a Universidade Federal de Pelotas (UFPeL) aderiu ao programa em dezembro de 2007 por compreender que a inclusão social, pela reestruturação do modelo universitário e pela expansão do acesso ao ensino superior gratuito e qualificado, são desafios pertinentes ao seu atual contexto (UNIVERSIDADE FEDERAL DE PELOTAS, 2007).

A adesão da UFPeL ao Programa REUNI tem provocado movimentos na cultura universitária impulsionados pelo significativo aumento de atores partícipes de sua comunidade acadêmica, associado ao relevante crescimento de sua infraestrutura básica para o desenvolvimento das atividades de ensino/pesquisa/extensão.

A resposta da UFPeL ao REUNI se deu a partir do reconhecimento da necessidade de ampliação de vagas de graduação e de criação de cursos noturnos para que possa ser capaz de responder com qualidade às demandas e expectativas locais e regionais.

Dentre as metas globais do REUNI, o Plano apresentado pela UFPeL se propunha a atingir a relação de 18,88 estudantes por professor, elevar a taxa de conclusão da graduação de 1,41 até 2012, ampliar a oferta de vagas nos cursos de graduação já existentes (diurnos e noturnos) e criação de 42 novos cursos de graduação (UNIVERSIDADE FEDERAL DE PELOTAS, 2007). 
Com a implantação do programa REUNI na UFPEL houve um incremento considerável, onde se destaca a oferta, em 2012, de 89 cursos de graduação, dos quais 32 são oferecidos no período noturno e o número de vagas ofertadas passou de 1931 em 2007, para 4.364 em 2012; assim, o incremento em relação a 2007 foi de mais 2.433 vagas de ingresso anual.

Importa sublinhar que com a expansão das universidades federais, houve um crescimento quantitativo sem paralelo na história da educação superior no Brasil, principalmente na UFPeL. Este crescimento se deu em um curto período de tempo, e esta situação provavelmente trará impactos que poderão ser considerados tanto positivos, quanto negativos.

É preciso entender que a educação, de modo geral, e, mais precisamente, a superior, necessita ser objeto permanente de olhares por parte da sociedade, dos governantes de nosso país e da comunidade onde está inserida. O papel desempenhado pela mesma, na busca do conhecimento para a construção da cidadania, precisa ser analisado de forma a não deixar de almejar o crescimento dos seres humanos como indivíduos livres e capazes de expressar suas ideias, pensamentos e ambições.

Aqui partimos do suposto que as políticas públicas para a educação superior necessitam ser eficazes e duradouras, e objeto de análise não somente dos órgãos fiscalizadores da execução financeira e administrativa, mas também da sociedade, a maior interessada nos resultados obtidos pelas instituições públicas.

Nesse contexto, cabe perguntar: o programa REUNI se constitui numa política de democratização do ensino superior no Brasil? Para responder a esta e a outras questões faz-se necessário e urgente que mecanismos de avaliação sejam operacionalizados de modo a contribuir tanto para a correção de possíveis desvios de metas, quanto para a consolidação e/ou qualificação dos objetivos já atingidos. Mas, indaga-se: quando será feita a avaliação deste programa? E mais: esta avaliação priorizará a dimensão econômico-financeira? Com isso chegamos ao seguinte problema: Quais são as dimensões, as variáveis e os indicadores que possibilitarão apresentar uma proposta de avaliação do eixo econômico-financeiro para o programa REUNI implementado na UFPeL, de forma a verificar a sua adequação ao proposto pelo Ministério da Educação, assim como as metas estabelecidas pela UFPeL.

Neste artigo, vamos aprofundar apenas as questões referentes à proposta de avaliação econômico-financeiro do programa REUNI na UFPeL, mas com certeza este será o início de um percurso que não terá volta e que potencializará outros trabalhos sobre o referido tema.

\section{A PROPOSTA DE AVALIAÇÃO}

A proposta de avaliação foi estruturada em duas importantes determinantes, a primeira é a metodologia da construção do instrumento de avaliação, que após o estabelecimento do eixo a ser avaliado, exigiu o aprofundamento dos conhecimentos sobre a temática para a definição da metodologia mais adequada de avaliação e, além disso, foi necessário definir aspectos como as dimensões a serem avaliadas, as variáveis e indicadores. A partir da definição da metodologia a ser utilizada passamos para a segunda determinante, a construção do instrumento de avaliação do eixo econômico-financeiro do Programa de Reestruturação e Expansão das Universidades Federais.

\subsection{Metodologia da construção do instrumento de avaliação}

A construção de um instrumento de avaliação para o Programa REUNI na UFPeL constitui parte de um esforço para melhorar a gestão da informação de programas e políticas para a expansão do ensino superior nesta Universidade, e, quem sabe, em outras instituições de ensino.

Ainda podemos dizer que, no mínimo, o objetivo mais amplo é de melhorar o desempenho do programa. Podemos considerar a proposta como uma inovação em dois sentidos: primeiro, na perspectiva da institucionalização da função avaliação e monitoramento como parte do processo de gestão de programas para educação superior na UFPeL; e segundo, na perspectiva da accountability, por meio da publicidade de indicadores de monitoramento, publicação dos resultados de estudos de avaliação e disponibilização à comunidade acadêmica e em geral de futuras pesquisas.

Vários foram os desafios enfrentados para a construção desse instrumento de avaliação em um contexto em que entra em jogo uma série de condições organizacionais e institucionais.

Para elaboração de um instrumento de análise, é fundamental identificar o tipo mais apropriado à política que se pretende avaliar. A seleção do caso a ser estudado foi intencionalmente direcionada.

A partir das leituras realizadas alguns aspectos foram levados em conta para a construção do instrumento de avaliação aqui proposto:

a) Determinação dos objetivos e conteúdos a serem avaliados. É a partir da definição dos objetivos que o pesquisador determina qual o tipo de instrumento mais adequado ao seu propósito;

b) Escolha das dimensões a serem utilizadas para que abranjam adequadamente as habilidades e os conhecimentos estudados; 
c) Fixação de variáveis para que abranjam adequadamente as habilidades $e$ os conhecimentos estudados, constituindose numa amostragem representativa dos conteúdos abordados;

d) Construção de indicadores que facilitem a elaboração das questões e instruções. Os indicadores devem ser redigidos de forma clara, precisa e concisa;

e) Elaboração de indicadores coerentes com os objetivos propostos. É importante assegurar a adequação do que será avaliado ao que foi definido pelo pesquisador; e

a) Revisão e aperfeiçoamento das dimensões, variáveis e indicadores.

Outro ponto que devemos considerar é que a liberdade do pesquisador é relativa e limitada à perspectiva em que a política foi formulada, ou seja, é o nível de racionalidade da formulação e o estilo de implementação que definem como ocorrerá a avaliação. Somente a partir desta identificação foi possível traçar uma metodologia que proporcionasse, posteriormente, condições de uma análise adequada e construção de parâmetros sobre a questão.

$\mathrm{O}$ primeiro passo foi o estabelecimento e aprofundamento da compreensão acerca do eixo a ser avaliado, o Econômico-Financeiro.

O eixo econômico-financeiro foi proposto pelo entendimento que o programa REUNI na UFPeL não tem como ser desenvolvido sem que os investimentos pelo Governo Federal sejam efetuados dentro do cronograma pré-definido. Sobretudo, no que se refere ao investimento público, cuja adequação entre objetivos, a forma de financiamento e os mecanismos de transferência de recursos, constitui importante fator de sucesso (SILVA; COSTA, 2002).

Seguindo a metodologia apresentada pelo Núcleo de Estudos em Políticas Públicas (NEPP), da UNICAMP (2005), foram utilizados dois conceitos fundamentais para a proposta de análise econômicofinanceira do programa REUNI na UFPeL. O primeiro é o de eficiência técnica para a execução econômicofinanceira, cujo objetivo é analisar a capacidade de produção, ou seja, os resultados que determinada quantidade de insumos é capaz de gerar ao longo do processo. E o segundo é a eficiência de alocação dos recursos, cujo objetivo é avaliar a adequação dos insumos utilizados em relação ao que foi produzido e demandado (UNIVERSIDADE ESTADUAL DE CAMPINAS, 2005).

\subsection{A proposta de avaliação do eixo econômico- financeiro}

Para favorecer a dinâmica do processo, o eixo financeiro foi desdobrado de forma a permitir a apreciação do desenvolvimento anual do programa e do final, incorporando o período compreendido pela sua realização.

O segundo passo foi o detalhamento do eixo, aproximando-o em dimensões operacionais. Foram estabelecidas quatro dimensões que estão presentes tanto no eixo econômico-financeiro anual, quanto no eixo econômico-financeiro total, os quais são:

b) Recursos financeiros investidos;

c) Repasses de recursos ao programa;

d) Execução orçamentária e financeira; e

e) Gestão e acompanhamento das metas acordadas.

O terceiro passo foi o desmembramento das dimensões em variáveis operativas, a partir das quais foi possível construir os indicadores e as fontes de coleta de informações, necessárias para dar conta da avaliação.

\subsubsection{Dimensão recursos financeiros investidos}

A dimensão recursos financeiros investidos gerou as seguintes variáveis: recursos projetados, descentralizados, executados e devolvidos; distribuição dos recursos projetados e executados pelo programa para pessoal; distribuição dos recursos projetados e executados pelo programa para bolsas; e distribuição dos recursos projetados e executados pelo programa para investimento.

Esta dimensão busca obter informações a respeito dos recursos econômico-financeiros executados de forma a confrontar com o que foi projetado. Ao mesmo tempo, tem como objetivo verificar a distribuição dos recursos nas diversas áreas que tiveram investimentos projetados, como por exemplo: contratação de pessoal e bolsas de assistência estudantil (Quadro 1).

\subsubsection{Dimensão repasse de recursos ao programa}

A dimensão repasses de recursos ao programa gerou a seguinte variável: regularidade com que os recursos são repassados ao programa. Esta dimensão busca obter informações sobre o repasse de recursos e a forma como ele se dá; busca, também, identificar problemas no repasse e a causa (Quadro 2).

\subsubsection{Dimensão execução orçamentária e financeira}

A dimensão execução orçamentária e financeira gerou a seguinte variável: Autonomia em relação à decisão sobre o investimento e execução financeira. Esta dimensão procura obter informações sobre a existência de determinação sobre os investimentos, apurar as responsabilidades em relação à programação do investimento bem como o cumprimento das metas (Quadro 3). 
Quadro 1 - Recursos financeiros investidos

\begin{tabular}{|c|c|c|}
\hline VARIÁVEIS & INDICADORES & FONTES \\
\hline \multirow{6}{*}{$\begin{array}{l}\text { Recursos projetados, } \\
\text { descentralizados, } \\
\text { executados } \\
\text { devolvidos pelo } \\
\text { programa REUNI na } \\
\text { UFPEL }\end{array}$} & $\begin{array}{l}\text { - Valor anual de recursos projetados pelo } \\
\text { programa REUNI na UFPEL }\end{array}$ & $\begin{array}{l}\text { - Coordenadoria do programa REUNI na } \\
\text { UFPEL }\end{array}$ \\
\hline & $\begin{array}{l}\text { - Valor anual de recursos } \\
\text { descentralizados/alocados pelo programa } \\
\text { REUNI para a UFPEL }\end{array}$ & $\begin{array}{l}\text { - Departamento de planejamento e } \\
\text { orçamento da UFPEL }\end{array}$ \\
\hline & $\begin{array}{l}\text { - Valor anual de recursos executados pelo } \\
\text { programa REUNI na UFPEL }\end{array}$ & $\begin{array}{l}\text { - Departamento de finanças e } \\
\text { contabilidade da UFPEL }\end{array}$ \\
\hline & $\begin{array}{l}\text { Valor anual de recursos devolvidos por falta } \\
\text { de execução ou saldo }\end{array}$ & $\begin{array}{l}\text { Departamento de planejamento e } \\
\text { orçamento e Departamento de finanças e } \\
\text { contabilidade da UFPEL }\end{array}$ \\
\hline & $\begin{array}{l}\text { - Investimento médio anual projetado pelo } \\
\text { programa REUNI para cada aluno } \\
\text { ingressante na UFPEL }\end{array}$ & $\begin{array}{l}\text { - Coordenadoria do programa REUNI e } \\
\text { departamento de registros acadêmicos da } \\
\text { UFPEL }\end{array}$ \\
\hline & $\begin{array}{l}\text { - Investimento médio anual executado pelo } \\
\text { programa REUNI para cada aluno } \\
\text { ingressante na UFPEL }\end{array}$ & $\begin{array}{l}\text { - Coordenadoria do programa REUNI, } \\
\text { Departamento de finanças e } \\
\text { contabilidade e departamento de registros } \\
\text { acadêmicos da UFPEL }\end{array}$ \\
\hline \multirow{9}{*}{$\begin{array}{l}\text { Distribuição dos } \\
\text { recursos projetados e } \\
\text { executados pelo } \\
\text { programa REUNI na } \\
\text { UFPEL para Pessoal }\end{array}$} & $\begin{array}{l}\text { - Valor anual de recursos projetados pelo } \\
\text { programa REUNI na UFPEL destinados a } \\
\text { contratação de pessoal }\end{array}$ & $\begin{array}{l}\text { - Coordenadoria do programa REUNI na } \\
\text { UFPEL }\end{array}$ \\
\hline & $\begin{array}{l}\text { - } \quad \% \text { anual de recursos executados pelo } \\
\text { programa REUNI na UFPEL para a } \\
\text { contratação de pessoal }\end{array}$ & $\begin{array}{l}\text { - Pró-Reitoria de Gestão de Recursos } \\
\text { Humanos }\end{array}$ \\
\hline & $\begin{array}{l}\text { Valor anual de recursos projetados pelo } \\
\text { programa REUNI na UFPEL destinados a } \\
\text { contratação de professor equivalente }\end{array}$ & $\begin{array}{l}\text { - Coordenadoria do programa REUNI na } \\
\text { UFPEL }\end{array}$ \\
\hline & $\begin{array}{l}\text { - } \% \text { anual de recursos executados pelo } \\
\text { programa REUNI na UFPEL para a } \\
\text { contratação de professor equivalente }\end{array}$ & $\begin{array}{l}\text { - Pró-Reitoria de Gestão de Recursos } \\
\text { Humanos }\end{array}$ \\
\hline & $\begin{array}{l}\text { - Valor anual de recursos projetados pelo } \\
\text { programa REUNI na UFPEL destinados a } \\
\text { contratação de servidores de nível superior }\end{array}$ & $\begin{array}{l}\text { - Coordenadoria do programa REUNI na } \\
\text { UFPEL }\end{array}$ \\
\hline & $\begin{array}{l}\text { - } \% \text { anual de recursos executados pelo } \\
\text { programa REUNI na UFPEL para a } \\
\text { contratação de servidores de nível superior }\end{array}$ & $\begin{array}{l}\text { - Pró-Reitoria de Gestão de Recursos } \\
\text { Humanos }\end{array}$ \\
\hline & $\begin{array}{l}\text { - Valor anual de recursos projetados pelo } \\
\text { programa REUNI na UFPEL destinados a } \\
\text { contratação de servidores de nível } \\
\text { intermediário }\end{array}$ & $\begin{array}{l}\text { - Coordenadoria do programa REUNI na } \\
\text { UFPEL }\end{array}$ \\
\hline & $\begin{array}{l}\text { - } \% \text { anual de recursos executados pelo } \\
\text { programa REUNI na UFPEL para a } \\
\text { contratação de servidores de nível } \\
\text { intermediário }\end{array}$ & $\begin{array}{l}\text { - Pró-Reitoria de Gestão de Recursos } \\
\text { Humanos }\end{array}$ \\
\hline & $\begin{array}{l}\text { - } \% \text { do valor destinado para a contratação de } \\
\text { professor equivalente em relação ao total de } \\
\text { recursos projetados para a contratação de } \\
\text { pessoal por ano }\end{array}$ & $\begin{array}{l}\text { - Coordenadoria do programa REUNI na } \\
\text { UFPEL }\end{array}$ \\
\hline
\end{tabular}


Continuação

\begin{tabular}{|c|c|c|}
\hline & $\begin{array}{l}\text { - } \% \text { do valor destinado para a contratação de } \\
\text { servidores de nível superior em relação ao } \\
\text { total de recursos projetados para a } \\
\text { contratação de pessoal por ano }\end{array}$ & $\begin{array}{l}\text { - Coordenadoria do programa REUNI na } \\
\text { UFPEL }\end{array}$ \\
\hline & $\begin{array}{l}\text { - } \% \text { do valor destinado para a contratação de } \\
\text { servidores de nível médio em relação ao total } \\
\text { de recursos projetados para a contratação de } \\
\text { pessoal por ano }\end{array}$ & $\begin{array}{l}\text { - Coordenadoria do programa REUNI na } \\
\text { UFPEL }\end{array}$ \\
\hline & $\begin{array}{l}\text { - } \% \text { do valor de recursos destinados para a } \\
\text { contratação de pessoal em relação ao total } \\
\text { de recursos projetados pelo programa REUNI } \\
\text { na UFPEL por ano }\end{array}$ & $\begin{array}{l}\text { - Coordenadoria do programa REUNI na } \\
\text { UFPEL }\end{array}$ \\
\hline \multirow{11}{*}{$\begin{array}{l}\text { Distribuição } \quad \text { dos } \\
\text { recursos projetados e } \\
\text { executados r pelo } \\
\text { programa REUNI na } \\
\text { UFPEL para Bolsas }\end{array}$} & $\begin{array}{l}\text { Valor anual de recursos projetados pelo } \\
\text { programa REUNI na UFPEL destinados ao } \\
\text { financiamento de bolsas }\end{array}$ & $\begin{array}{l}\text { - Coordenadoria do programa REUNI na } \\
\text { UFPEL }\end{array}$ \\
\hline & $\begin{array}{l}\text { - } \% \text { anual de recursos executados pelo } \\
\text { programa REUNI na UFPEL para a } \\
\text { concessão de bolsas }\end{array}$ & $\begin{array}{l}\text { - Pró-Reitora de Pós-Graduação, Pró- } \\
\text { Reitoria de Assuntos Estudantis e } \\
\text { Coordenadoria do programa REUNI na } \\
\text { UFPEL }\end{array}$ \\
\hline & $\begin{array}{l}\text { - Valor anual de recursos projetados pelo } \\
\text { programa REUNI na UFPEL destinados ao } \\
\text { financiamento de bolsas de assistência } \\
\text { estudantil }\end{array}$ & $\begin{array}{l}\text { - Coordenadoria do programa REUNI na } \\
\text { UFPEL }\end{array}$ \\
\hline & $\begin{array}{l}\text { - } \% \text { anual de recursos executados pelo } \\
\text { programa REUNI na UFPEL para a } \\
\text { concessão de bolsas de assistência } \\
\text { estudantil }\end{array}$ & $\begin{array}{l}\text { - Pró-Reitoria de Assuntos Estudantis e } \\
\text { Departamento de planejamento e } \\
\text { orçamento }\end{array}$ \\
\hline & $\begin{array}{l}\text { Valor anual de recursos projetados pelo } \\
\text { programa REUNI na UFPEL destinados ao } \\
\text { financiamento de bolsas de Mestrado }\end{array}$ & $\begin{array}{l}\text { - Coordenadoria do programa REUNI na } \\
\text { UFPEL }\end{array}$ \\
\hline & $\begin{array}{l}\text { - } \quad \text { anual de recursos executados pelo } \\
\text { programa REUNI na UFPEL para a } \\
\text { concessão de bolsas de Mestrado }\end{array}$ & $\begin{array}{l}\text { - Pró-Reitora de Pós-Graduação e } \\
\text { Coordenadoria do programa REUNI na } \\
\text { UFPEL }\end{array}$ \\
\hline & $\begin{array}{l}\text { Valor anual de recursos projetados pelo } \\
\text { programa REUNI na UFPEL destinados ao } \\
\text { financiamento de bolsas de Doutorado }\end{array}$ & $\begin{array}{l}\text { - Coordenadoria do programa REUNI na } \\
\text { UFPEL }\end{array}$ \\
\hline & $\begin{array}{l}\text { - } \% \text { anual de recursos executados pelo } \\
\text { programa REUNI na UFPEL para a } \\
\text { concessão de bolsas de Doutorado }\end{array}$ & $\begin{array}{l}\text { - Pró-Reitora de Pós-Graduação e } \\
\text { Coordenadoria do programa REUNI na } \\
\text { UFPEL }\end{array}$ \\
\hline & $\begin{array}{l}\text { - } \% \text { do valor destinado para bolsas de } \\
\text { assistência estudantil em relação ao total de } \\
\text { recursos projetados para o financiamento de } \\
\text { bolsas na UFPEL por ano }\end{array}$ & $\begin{array}{l}\text { - Coordenadoria do programa REUNI na } \\
\text { UFPEL }\end{array}$ \\
\hline & $\begin{array}{l}\text { - } \% \text { do valor destinado para bolsas de } \\
\text { mestrado em relação ao total de recursos } \\
\text { projetados para o financiamento de bolsas na } \\
\text { UFPEL por ano }\end{array}$ & $\begin{array}{l}\text { - Coordenadoria do programa REUNI na } \\
\text { UFPEL }\end{array}$ \\
\hline & $\begin{array}{l}\text { - } \quad \text { do valor destinado para bolsas de } \\
\text { doutorado em relação ao total de recursos } \\
\text { projetados para o financiamento de bolsas na }\end{array}$ & $\begin{array}{l}\text { - Coordenadoria do programa REUNI na } \\
\text { UFPEL }\end{array}$ \\
\hline
\end{tabular}


Continuação

\begin{tabular}{|c|c|c|}
\hline & UFPEL por ano & \multirow[b]{2}{*}{$\begin{array}{l}\text { - Coordenadoria do programa REUNI na } \\
\text { UFPEL }\end{array}$} \\
\hline & $\begin{array}{l}\text { \% do valor de recursos destinados a bolsas } \\
\text { em relação ao total de recursos projetados } \\
\text { pelo programa REUNI na UFPEL por ano }\end{array}$ & \\
\hline \multirow{7}{*}{$\begin{array}{l}\text { Distribuição dos } \\
\text { recursos projetados e } \\
\text { executados pelo } \\
\text { programa REUNI na } \\
\text { UFPEL } \\
\text { Investimento }\end{array}$} & $\begin{array}{l}\text { - Valor anual de recursos projetados pelo } \\
\text { programa REUNI na UFPEL destinados a } \\
\text { construção edificações }\end{array}$ & $\begin{array}{l}\text { - Coordenadoria do programa REUNI na } \\
\text { UFPEL }\end{array}$ \\
\hline & $\begin{array}{l}\text { - } \% \text { anual de recursos executados pelo } \\
\text { programa REUNI na UFPEL para a } \\
\text { construção edificações }\end{array}$ & $\begin{array}{l}\text { - Coordenadoria do programa REUNI na } \\
\text { UFPEL e Departamento de planejamento } \\
\text { e Orçamento }\end{array}$ \\
\hline & $\begin{array}{l}\text { - Valor anual de recursos projetados pelo } \\
\text { programa REUNI na UFPEL destinados a } \\
\text { manutenção da infraestrutura }\end{array}$ & $\begin{array}{l}\text { - Coordenadoria do programa REUNI na } \\
\text { UFPEL }\end{array}$ \\
\hline & $\begin{array}{l}\text { - } \% \text { anual de recursos executados pelo } \\
\text { programa REUNI na UFPEL para a } \\
\text { manutenção da infraestrutura }\end{array}$ & $\begin{array}{l}\text { - Coordenadoria do programa REUNI na } \\
\text { UFPEL e Departamento de planejamento } \\
\text { e Orçamento }\end{array}$ \\
\hline & $\begin{array}{l}\text { - Valor anual de recursos projetados pelo } \\
\text { programa REUNI na UFPEL destinados a } \\
\text { aquisição de equipamentos }\end{array}$ & $\begin{array}{l}\text { - Coordenadoria do programa REUNI na } \\
\text { UFPEL }\end{array}$ \\
\hline & $\begin{array}{l}\text { - } \% \text { anual de recursos executados pelo } \\
\text { programa REUNI na UFPEL para aquisição } \\
\text { de equipamentos }\end{array}$ & $\begin{array}{l}\text { - } \quad \text { Coordenadoria do programa REUNI na } \\
\text { UFPEL e Departamento de planejamento } \\
\text { e Orçamento }\end{array}$ \\
\hline & $\begin{array}{l}\text { Valor anual de recursos projetados pelo } \\
\text { programa REUNI na UFPEL destinados a } \\
\text { investimento }\end{array}$ & $\begin{array}{l}\text { - Coordenadoria do programa REUNI na } \\
\text { UFPEL }\end{array}$ \\
\hline \multirow{5}{*}{$\begin{array}{l}\text { Distribuição dos } \\
\text { recursos projetados e } \\
\text { executados pelo } \\
\text { programa REUNI na } \\
\text { UFPEL } \\
\text { Investimento para } \\
\text { (continuação) }\end{array}$} & $\begin{array}{l}\text { - } \% \text { anual de recursos executados pelo } \\
\text { programa REUNI na UFPEL para } \\
\text { investimento }\end{array}$ & $\begin{array}{l}\text { - Coordenadoria do programa REUNI na } \\
\text { UFPEL e Departamento de planejamento } \\
\text { e Orçamento }\end{array}$ \\
\hline & $\begin{array}{l}\text { \% do valor destinado para a construção de } \\
\text { edificações em relação ao total de recursos } \\
\text { projetados para investimento por ano }\end{array}$ & $\begin{array}{l}\text { - Coordenadoria do programa REUNI na } \\
\text { UFPEL }\end{array}$ \\
\hline & $\begin{array}{l}\text { - } \% \text { do valor destinado para a manutenção da } \\
\text { infraestrutura em relação ao total de recursos } \\
\text { projetados para investimento por ano }\end{array}$ & $\begin{array}{l}\text { - Coordenadoria do programa REUNI na } \\
\text { UFPEL }\end{array}$ \\
\hline & $\begin{array}{l}\text { - } \% \text { do valor destinado para aquisição de } \\
\text { equipamentos em relação ao total de } \\
\text { recursos projetados para investimento por } \\
\text { ano }\end{array}$ & $\begin{array}{l}\text { - Coordenadoria do programa REUNI na } \\
\text { UFPEL }\end{array}$ \\
\hline & $\begin{array}{l}\text { - } \% \text { do valor de recursos destinados para } \\
\text { investimento em relação ao total de recursos } \\
\text { projetados pelo programa REUNI na UFPEL } \\
\text { por ano }\end{array}$ & $\begin{array}{l}\text { - Coordenadoria do programa REUNI na } \\
\text { UFPEL }\end{array}$ \\
\hline
\end{tabular}

Fonte: Elaborados pelos autores

\subsubsection{Dimensão gestão e acompanhamento das metas acordadas}

E por fim, a dimensão gestão e acompanhamento das metas acordadas gerou as seguintes variáveis: metas acordadas e acompanhamento das metas acordadas. Esta dimensão tem como objetivo identificar a existência de metas, a possibilidade de reprogramá-las e a existência de responsabilização pelo não cumprimento de metas. Além disso, procura identificar rotinas de acompanhamento das metas bem como de prestação de contas e a causa da não aplicação dos recursos (Quadro 4). 
Quadro 2 - Repasse de recursos ao programa

\begin{tabular}{|c|c|c|}
\hline VARIÁVEL & INDICADORES & FONTES \\
\hline \multirow{8}{*}{$\begin{array}{l}\text { Regularidade com que } \\
\text { os recursos são repas- } \\
\text { sados ao programa }\end{array}$} & $\begin{array}{l}\text { - Existência de periodicidade de re- } \\
\text { passes (sim/não) }\end{array}$ & $\begin{array}{l}\text { - Departamento de planejamento e orçamento e } \\
\text { Departamento de finanças e contabilidade da } \\
\text { UFPEL }\end{array}$ \\
\hline & $\begin{array}{l}\text { Periodicidade do repasse (mensal, } \\
\text { bimestral, trimestral, semestral e anual) }\end{array}$ & $\begin{array}{l}\text { Departamento de planejamento e orçamento e } \\
\text { Departamento de finanças e contabilidade da } \\
\text { UFPEL }\end{array}$ \\
\hline & $\begin{array}{ll}\text { - Existência de desembolso pela UFPEL } \\
\text { (sim/não) }\end{array}$ & $\begin{array}{l}\text { - Departamento de planejamento e orçamento } \\
\text { da UFPEL }\end{array}$ \\
\hline & - $\quad$ Adequação repasses e desembolsos & $\begin{array}{l}\text { Departamento de planejamento e orçamento } \\
\text { e Departamento de finanças e contabilidade e } \\
\text { Coordenadoria do programa REUNI na UFPEL }\end{array}$ \\
\hline & $\begin{array}{l}\text { Existência de condicionamento dos } \\
\text { recursos ao cumprimento das metas } \\
\text { (sim/não) }\end{array}$ & - $\quad$ Coordenadoria do programa REUNI na UFPEL \\
\hline & $\begin{array}{l}\text { - Houve cancelamento nos repasses por } \\
\text { descumprimento das condicionalidades } \\
\text { (sim/não) }\end{array}$ & $\begin{array}{l}\text { Departamento de planejamento e orçamento e } \\
\text { Coordenadoria do programa REUNI na UFPEL }\end{array}$ \\
\hline & $\begin{array}{l}\text { - Número de vezes que houve atraso no } \\
\text { repasse }\end{array}$ & $\begin{array}{l}\text { - Departamento de planejamento e orçamento e } \\
\text { Coordenadoria do programa REUNI na UFPEL }\end{array}$ \\
\hline & - Justificativa para os atrasos & - $\quad$ Coordenadoria do programa REUNI na UFPEL \\
\hline
\end{tabular}

Fonte: Elaborados pelos autores

Quadro 3 - Execução orçamentária e financeira

\begin{tabular}{|c|c|c|}
\hline VARIÁVEL & INDICADORES & FONTES \\
\hline \multirow{5}{*}{$\begin{array}{l}\text { Autonomia em } \\
\text { relação à decisão } \\
\text { sobre o investi- } \\
\text { mento e execução } \\
\text { financeira }\end{array}$} & $\begin{array}{l}\text { - Existência de determinação sobre os investi- } \\
\text { mentos (sim/não) }\end{array}$ & - $\quad$ Coordenadoria do programa REUNI na UFPEL \\
\hline & $\begin{array}{l}\text { Execução centralizada na administração } \\
\text { central da universidade ou descentralizada } \\
\text { nas unidades acadêmicas }\end{array}$ & - Coordenadoria do programa REUNI na UFPEL \\
\hline & $\begin{array}{l}\text { - Setores responsáveis pela programação do } \\
\text { investimento }\end{array}$ & - Coordenadoria do programa REUNI na UFPEL \\
\hline & $\begin{array}{l}\text { - Setores responsáveis pelo planejamento e } \\
\text { cumprimento das metas }\end{array}$ & - $\quad$ Coordenadoria do programa REUNI na UFPEL \\
\hline & $\begin{array}{l}\text { Existência de mecanismos que permitam a } \\
\text { reprogramação de recursos devolvidos ao } \\
\text { órgão financiador }\end{array}$ & - Ministério da Educação/MEC \\
\hline
\end{tabular}

Fonte: Elaborados pelos autores

Quadro 4 - Gestão e acompanhamento das metas acordadas

\begin{tabular}{|c|c|c|}
\hline VARIÁVEIS & INDICADORES & FONTES \\
\hline \multirow{4}{*}{ Metas acordadas } & $\begin{array}{l}\text { Existência de metas acordadas e a forma de } \\
\text { acordo }\end{array}$ & - Coordenadoria do programa REUNI na UFPEL \\
\hline & $\begin{array}{l}\text { - Existência de incentivo ao cumprimento das } \\
\text { metas (sim/não) }\end{array}$ & - Coordenadoria do programa REUNI na UFPEL \\
\hline & $\begin{array}{l}\text { - Existência de reprogramação de metas (sim/ } \\
\text { não) }\end{array}$ & $\begin{array}{l}\text { - Coordenadoria do programa REUNI na UFPEL } \\
\text { e Ministério da Educação/MEC }\end{array}$ \\
\hline & $\begin{array}{l}\text { - Existência de responsabilização pelo não cum- } \\
\text { primento das metas acordadas (sim/não) }\end{array}$ & $\begin{array}{l}\text { - Coordenadoria do programa REUNI na UFPEL } \\
\text { e Ministério da Educação/MEC }\end{array}$ \\
\hline \multirow{4}{*}{$\begin{array}{l}\text { Acompanhamento } \\
\text { das metas acorda- } \\
\text { das }\end{array}$} & $\begin{array}{l}\text { - Existência de mecanismos de prestação de } \\
\text { contas }\end{array}$ & $\begin{array}{l}\text { - } \quad \text { Coordenadoria do programa REUNI na UFPEL } \\
\text { e Departamento de Finanças e Contabilidade }\end{array}$ \\
\hline & $\begin{array}{l}\text { - Existência de uma rotina de acompanhamento } \\
\text { das metas (sim/não) }\end{array}$ & - Coordenadoria do programa REUNI na UFPEL \\
\hline & $\begin{array}{l}\text { - Periodicidade da rotina de acompanhamento } \\
\text { das metas (sim/não) }\end{array}$ & - Coordenadoria do programa REUNI na UFPEL \\
\hline & $\begin{array}{l}\text { - Causa da não aplicação dos recursos devolvi- } \\
\text { dos }\end{array}$ & - Coordenadoria do programa REUNI na UFPEL \\
\hline
\end{tabular}

Fonte: Elaborados pelos autores 


\section{CONCLUSÃO}

A educação em nosso país ainda que por muitas vezes tenha servido de estratégia política para o alcance de metas e objetivos governamentais, decorrentes, na maioria das vezes, de acordos internacionais, provavelmente o marco central das atuais políticas para o setor educacional brasileiro e, mais especificamente, para a educação superior, esteja no fato da centralidade do Estado neste processo.

Nesta direção, uma das primeiras sinalizações extraídas da pesquisa realizada diz respeito à histórica situação de precariedade vivida pelo ensino superior. Tal situação pode ser entendida pelo menos em grande parte pela ausência da ação do Estado e, por consequência, a falta de responsabilidade e de cumprimento dos direitos do cidadão brasileiro.

A busca pela efetivação do direito fundamental à educação como instrumento de transformação social deve ser o "carro chefe" das políticas públicas do Estado brasileiro, com a implantação de um processo educacional inclusivo baseado no sujeito como ser consciente e pensante. Ou seja, deve proporcionar ao indivíduo a oportunidade de igualdade de condições para que se torne efetivamente um cidadão.

Diante das possibilidades de contribuição da educação como política pública na construção de uma cidadania participativa e democrática, sustentada em princípios de justiça e igualdade de direitos, o Estado brasileiro nos últimos anos está trilhando um caminho que busca a obtenção da redução das desigualdades, e procura realizar isso através de investimentos em uma educação pública, gratuita, universal e de qualidade.

Podemos constatar algumas medidas adotadas ao identificarmos a ampliação do número de vagas ofertadas nos cursos de graduação das universidades federais e, principalmente, a criação de cursos noturnos ofertados nas instituições federais de ensino superior.

Temos a certeza que em um período bem próximo poderemos visualizar as consequências positivas da implementação das políticas que tratam da expansão do ensino superior no Brasil. As alterações serão significativas em virtude das transformações que estão ocorrendo, podendo potencializar o acesso de trabalhadores e jovens residentes em regiões onde antes não havia universidade. Aqui podemos destacar como exemplo o processo de interiorização do ensino superior público.

Nesse contexto, mesmo não incluindo a todos neste momento, o processo que estamos vivenciando será de grande valia se pudermos avaliar e analisar os possíveis aspectos negativos e positivos, e com base nos resultados obtidos, contribuir para a elaboração e reajuste de políticas sociais voltadas ao acesso à educação superior do nosso país.
Assim, a inclusão social, a reestruturação do modelo universitário e a expansão do acesso ao ensino superior gratuito e qualificado, são desafios pertinentes ao atual contexto brasileiro, onde se visa transformar não somente o perfil dos futuros egressos como também participar de forma efetiva nas ações necessárias para o desenvolvimento social, econômico e político.

Com a pesquisa realizada identificamos a importância da realização de avaliação bem como alguns desafios deste processo. O maior obstáculo para que a avaliação de políticas públicas seja disseminada e passe a fazer parte do cotidiano, está ligado à dificuldade de se encontrar formas de mensurar o desempenho das ações e fornecer subsídios aos gestores e atores envolvidos no processo de elaboração e implementação das políticas. E esta dificuldade tende a levar as avaliações para um viés de alcance de metas e objetivos.

Uma metodologia de avaliação de políticas públicas e programas sociais passa pela escolha de critérios e pela definição de indicadores consistentes com os critérios selecionados. Ela deve ainda possibilitar uma análise de forma contínua para que padrões de desempenho possam ser comparados.

A utilização de um sistema amplo de indicadores sociais relevantes, válidos e confiáveis possibilita o aumento das chances de sucesso tanto na etapa de formulação da política quanto na de implementação. Os indicadores sociais podem fornecer diagnósticos sociais, controlar os resultados dos programas sociais, além de embasarem os resultados das avaliações realizadas.

Além disso, na época em que os governantes justificavam a falta de políticas públicas pelo déficit orçamentário que a implementação destas poderia causar, a avaliação torna-se definitivamente um importante instrumento de combate à "desculpa" meramente econômica para a falta de investimento em programas sociais.

Na educação, como visto durante a pesquisa, os investimentos, assim como em outras áreas, também foram reduzidos sob um contexto de retração da atividade econômica, seguindo uma orientação neoliberal. Neste sentido, o projeto era de desqualificação do ensino público federal, como forma de justificar a privatização deste serviço.

Acreditamos que a proposta apresentada, de avaliação econômico-financeira do programa REUNI na UFPeL, trará avanços na execução do programa no sentido de fornecer subsídios em relação a problemas que poderão ser encontrados na alocação, distribuição e execução dos recursos financeiros. Pois, tanto os investimentos do governo federal, assim como a adequação do que foi proposto com o executado, são fatores fundamentais para o sucesso da política implementada. 
A construção do instrumento de avaliação permitiu estabelecer a compatibilidade entre os conteúdos relativos ao Programa REUNI contidos nos documentos da UFPeL e do Ministério da Educação.

Outro aspecto importante a ser observado como resultado deste trabalho diz respeito à institucionalização da cultura de avaliação e monitoramento de programas e políticas para a educação superior.

Acreditamos que os parâmetros apresentados no eixo econômico-financeiro poderão ser utilizados para avaliar o eixo citado, em outras instituições e programas educacionais.

Por fim, entendemos como sendo de responsabilidade de todos, e de cada um de nós, a efetiva participação nos processos de construção que envolve a discussão de questões inerentes ao desenvolvimento e qualificação da instituição pública, seus cursos, seus programas e seus projetos.

\section{REFERÊNCIAS}

BRASIL. Decreto $n^{\circ}$ 6.096, de 24 de abril de 2007. Institui o Programa de Apoio a Planos de Reestruturação e Expansão das Universidades Federais - REUNI. Diário Oficial da União, Brasília, DF, 25 abr. 2007. Disponível em:<http://camara.gov. br>. Acesso em: 20 maio 2011.

Lei $n^{\circ} 10.172$, de 09 de janeiro de 2001. Aprova o Plano Nacional de Educação e dá outras providências. Diário Oficial da União, Brasília, DF, 10 jan. 2001. Disponível em:<http://camara.gov.br>. Acesso em: 22 maio 2011.

INSTITUTO NACIONAL DE ESTUDOS E PESQUISAS EDUCACIONAIS ANÍSIO TEIXEIRA. Conceitos e descrição, avaliação institucional das IES, Sinaes, 2009. Brasília, DF, 2008. Disponível em:<http://www.inep.gov.br/download/ superior/2008/instrumento_de_avaliação_ externa. pdf> . Acesso em: 20 set. 2011.

Site [on-line]. Brasília, DF, [2011?]. Disponível em: <http://inep.gov.br> Acesso em: 26 maio 2011.

SILVA, P. L. B.; Costa, N. R. A avaliação de programas públicos: reflexões sobre a experiência Brasileira - relatório técnico. Brasília, DF: IPEA, 2002.

UNIVERSIDADE CATÓLICA DE PELOTAS. Plano de Reestruturação e Expansão da Universidade Federal de Pelotas para o período 2008-2012. Pelotas, RS, 2007.
UNIVERSIDADE ESTADUAL DE CAMPINAS. Núcleo de Estudos em Políticas Públicas. Efetividade do desenvolvimento do setor saúde: experiências bem-sucedidas na América Latina e Caribe. Caderno de Pesquisa, São Paulo, n. 70, 2005. Disponível em:<http://www.nepp.unicamp.br>. Acesso em: 2 dez. 2011.

\section{João Carlos de Oliveira Koglin}

Analista de Sistema

Mestre em Política Social pela Universidade Católica de Pelotas (UCPEL)

Professor Assistente do Centro de Integração do Mercosul e Coordenador do Programa REUNI na Universidade Federal de Pelotas (UFPEL)

E-mail: joaokoglin@yahoo.com.br

\section{Vera Maria Ribeiro Nogueira}

Assistente Social

Professora Adjunta da Escola de Serviço Social/Programa de Mestrado em Política Social da Universidade Católica de Pelotas (UCPEL) e do Mestrado em Política Social do Departamento de Serviço Social da Universidade Federal de Santa Catarina (UFSC)

E-mail: vera.nogueira@pq.cnpq.br

\section{Universidade Federal de Pelotas (UFPEL)}

Rua Gomes Carneiro, 1, Centro - Pelotas, RS CEP: $96010-610$

Universidade Federal de Santa Catarina (UFSC)

Campus Universitário Reitor João David Ferreira Lima Trindade - Florianópolis - SC

CEP: $88040-900$ 